\title{
Achieving Steady and Stable Energy from AlGaAsGaAs Solar Cells
}

\author{
M. Sojoudi \\ Electrical Engineering Dpt, \\ Azerbaijan Higher \\ Education \& Research \\ Complex, Iran \\ Mosaddegh_sojoudi@yaho \\ o.com
}

\author{
R. Madatov \\ Inistitute of Radiation \\ Problems, \\ National Science Academy \\ of Azerbaijan, \\ Baku, Azerbaijan \\ msrahim@mail.ru
}

\author{
T. Sojoudi \\ Young Researchers Club, \\ Parsabad Moghan Branch \\ Islamic Azad University \\ Parsabad Moghan, Iran \\ tsojoudi@iaupmogan.ac.ir
}

\author{
P. Farhadi \\ Young Researchers Club, \\ Parsabad Moghan Branch \\ Islamic Azad University \\ Parsabad Moghan, Iran \\ pfarhadi@iaupmogan.ac.ir
}

\begin{abstract}
The hetero junction operating as a solar cell is based on n-GaAs-p-GaAs-p- $\mathrm{Al}_{0.75} \mathbf{G a}_{0.25}$ As. This paper investigates the influence of radiation electron ray on layers of hetero-junction AlGaAsGaAs. Long term operation in the radiation zone degrades solar cell power operating parameters and reduces overall cell's life. The impact of radiation electron ray has been analyzed with various doses on layers of the AlGaAsGaAs hetero-junction. V-A characteristics and parameters such as the photocurrent density (Jsc), voltage at open circuit (Voc) and energy conversion efficiency $(\eta(\eta)$, are evaluated for different doses of electron radiations. It is shown that current and voltage decrease when irradiation doses increase. Further, Jsc and $\eta$ parameters decrease proportionally to the increase of the electron radiation doses whereas $V o c$ is only slightly decreased.
\end{abstract}

Keywords: solar cells; hetero-junction; electron rays; V-I characteristics; steady and stable snergy.

\section{INTRODUCTION}

The sun is a staggering amount of free, environmentally friendly, quiet and reliable energy supply and the use of solar electricity to produce a substantial portion of the required electrical power has been proposed since 1970 [1]. Earth's ultimate recoverable resource of oil is estimated at 3 trillion barrels, which equals to $1.7 \times 10^{22}$ joules of energy, which the sun delivers in only 1.5 days [2]. Since $120,000 \mathrm{TW}$ of solar radiation strike the surface of the Earth, a $10 \%$ efficient solar conversion systems covering $0.16 \%$ of the land would produce $20 \mathrm{TW}$ of power, nearly twice the annual global energy consumption [3].

High efficiency solar cells use multiple materials with band gaps that span the solar spectrum. Multi-junction solar cells are composed of some single-junction solar cells stacked upon each other, so that each layer going from the top to the bottom has a smaller band gap than the previous, and absorbs and converts the photons that have energies greater than the band gap of that layer and less than the band gap of the higher layer [4].
Triple-junction solar cells currently in production are made of GaInP (1.9 eV), GaAs (1.4 eV), and Ge (0.7 eV); advanced multi-junction solar cell concepts anticipate use of AlGaInP (2.2 eV), AlGaAs (1.6 eV), GaInP (1.7 eV), GaInAs (1.2 eV), GaInNAs (1.0-1.1 eV) [5]. Though solar cells (SC) are prepared on the basis of $A^{3} B^{5}$ compounds and their solid solutions are used in different technical fields, the problem of their radiation resistance still remains.

Degradation of operation parameters and decrease of cell's life time is observed during long-term operation of the cell in the radiation zone due to the decrease of the inner quantum effect, the generation and recombination processes and the increase of surface recombination velocity in the junction area. On the other hand, it should be taken into account that the degradation of the structure parameters $\left(\beta, R\right.$ and $\left.j_{0}\right)$ depends on the nature of structural defects, probability of complexes' formation and interaction of defects. Namely from this reason, in spite of using different methods to increase radiation resistance of raw material, the problem has not found its solution. For this purpose, the influence of accelerated electron rays on the photoelectric properties of the SC prepared on the basis of AlGaAs-GaAs is investigated [6-10].

\section{GENERAL EXPLANATIONS OF CELL PROPERTIES}

The photocurrent generated by a solar cell under illumination at short circuit is dependent on the incident light. To relate the photocurrent density, Jsc, to the incident spectrum we need the cell's quantum efficiency, $(\mathrm{QE}) . \mathrm{QE}(\mathrm{E})$ is the probability that an incident photon of energy $\mathrm{E}$ will deliver one electron to the external circuit.

The photocurrent density is given by:

$$
\mathrm{J}_{\mathrm{SC}}=\mathrm{q} \int \mathrm{b}_{\mathrm{S}}(\mathrm{E}) \mathrm{Q}(\mathrm{E}) \mathrm{dE}
$$

where $b_{s}(\mathrm{E})$ is the incident spectral photon flux density, the number of photons of energy in the range $E$ to $E+d E$ which are incident on unit area in unit time, and $q$ is the electronic charge. $Q E$ depends upon the absorption coefficient 
of the solar cell material, the efficiency of charge separation and the efficiency of charge collection in the device, but not on the incident spectrum. It is therefore a key quantity in order to describe solar cell performance under different conditions. $Q E$ and spectrum can be given as functions of either photon energy or wavelength $\lambda$. Energy is a more convenient parameter for the physics of solar cells and it will be used in this paper. The relationship between $E$ and $\lambda$ is given by:

$$
\mathrm{E}=\frac{\mathrm{hc}}{\lambda}
$$

where $h$ is Planck's constant and $c$ is the speed of light in vacuum. A convenient rule for converting between photon energies, in electron-Volts, and wavelengths, in $\mathrm{nm}$, is given by $E / e v=240 /(\lambda / n m)$.

\section{HETERO-JUNCTION AND ELECTRON RADIATION RAY}

Several techniques are employed to produce solar cells of $A^{3} B^{5}$ complex, and their solid solution used in different fields of technology, and the problem to have a steady radiation still remains unsolved. It has been found that the power operating parameters of solar cells are degraded after a long-term operation in the radiation zone which in turn results in a reduced life time of the cell. Because of the reduction of inner activity, production process and recombination as well as velocity of recombination will be increased in the junction. In Lux-Ampere characteristic $V_{o c}$ and $J_{s c}$ will vary at different irradiation doses. $V_{o c}$ and $J_{s c}$ will increase with the increase of electron radiation dose at the Lux constant amount. In addition, the quality degradation of structural parameters $\left(\beta, R, J_{0}\right)$ which modifies the structure and depends on the nature of structure defects and the probability of complex layers and their impact should be considered. To research this issue, the influence of accelerated electron ray on properties of photoelectric for AlGa-GaAs is investigated.

The hetero-junction has been prepared on the base of n-GaAs-p-GaAs-p- $\mathrm{Al}_{0.75} \mathrm{Ga}_{0.25} \mathrm{As}$. The $\mathrm{n}$-GaAs layer with a density of $n=1-3 \times 10^{17} \mathrm{~cm}^{-3}$ is on the layer of Zinc, with a thickness $15-20 \mu m$ as a solid solution. The thickness of $p-G a A s$ layer is $1 \mu \mathrm{m}$. During construction zinc metal powder is poured on its surface. Zinc layer is placed to reduce thickness of player, with high concentration and low contact resistance. The case study surface is $2 \mathrm{~cm}^{2}$.

At the firm of measurement, the curve of electrical characteristics of solar radiation spectrum $\left(A M_{-1,5}\right)$ is used to determine the V-I characteristics of solar cells under the uniform radiation. This solar cell is uniform under radiation with power of $\mathrm{p}_{\mathrm{g}}=91 \mathrm{mw} / \mathrm{cm}^{2}, J_{s c}=20-25 \mathrm{~mA} / \mathrm{cm}^{2}, V_{o c}=0.92-0.95$ $(V)$ and efficiency $\eta=16-20 \%$. This sample was under radiation with electric energy $4.5 \mathrm{Mev}$ by electron ray of ELIT-6 equipment. The $\mathrm{n}-\mathrm{GaAs}-\mathrm{p}-\mathrm{GaAs}-\mathrm{P}-\mathrm{Al}_{0.75} \mathrm{Ga}_{0.25} \mathrm{As}$ solar cell structure has been checked by different kinds of V-I characteristics by electron rays.

\section{VARIOUS DOSES OF RADIATION}

Solar cell's $V-I$ characteristics have been illustrated in Figure 1 before and after irradiation. Increasing the electron ray dose causes $J_{S c}$ to decrease, while Voc is slightly changed.

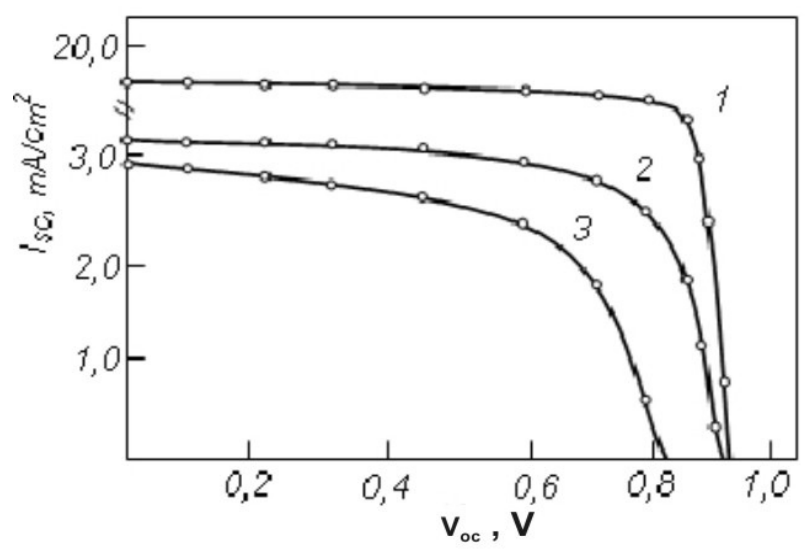

Fig. 1. V-I characteristics of solar cell before and after irradiation: 1. $0,2.10^{15}, 3 \cdot 10^{16}\left(\mathrm{el} / \mathrm{cm}^{2}\right)$

The parameters calculated according to the curves of Figure 1, independently to the radiation dose, are shown in Figure 2. It is shown that the influence of electron rays on solar cells cause a significant alteration in $J S c$ while $V o c$ is only slightly altered. $J_{S c}(p)$ and $\operatorname{Voc}(p)$ are functions of electron ray radiation and because of the electron ray, the photo current variation is observed as shown in curves 1-3 of Figure 4.

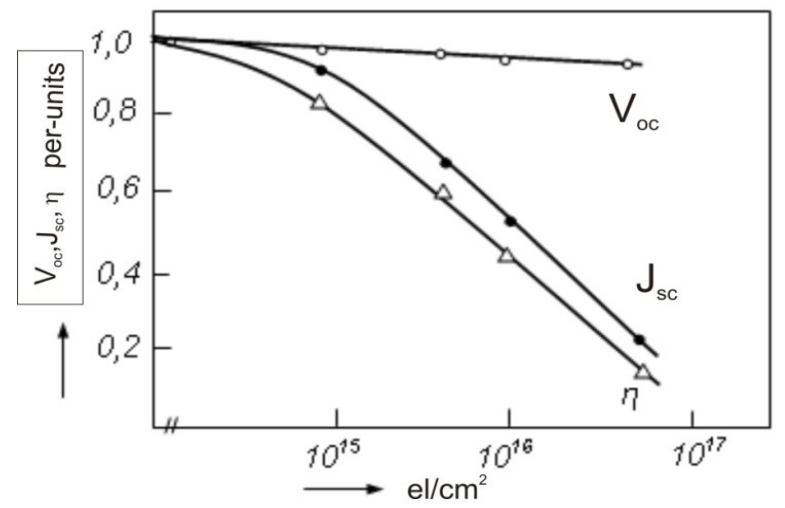

Fig. 2. Dependence of Jsc, Voc, $\eta$ on the different radiation

From Figure 3 it can be observed that the change of $\operatorname{Voc}(p)$ depending on the radiation dose is about $20 \%$ in comparison to $J_{s c}(p)$. As in the irradiated samples at the results of an isochronous sealing $(\mathrm{T}=4000 \mathrm{C}, \mathrm{t}=30 \mathrm{~min}) J_{S c}$ is not completely recovered which is justified by the fact that the radiation defects formed in $\mathrm{p}-\mathrm{A} 10.75 \mathrm{Ga} 0.25$ layer is much more resistant. Comparing theoretical and practical results reveals that defects caused by electron ray radiation exist on $\mathrm{p}-\mathrm{A} 10.75 \mathrm{Ga} 0.25$ region with wide band gap. To explain this fact, the influence of electron radiation on the spectral characteristic of these elements has been investigated. 


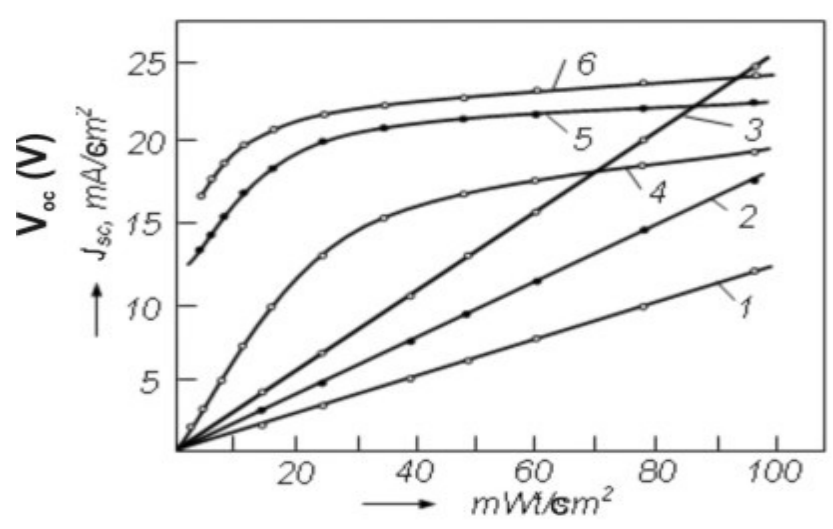

Fig. 3. Lux-ampere characteristics at different irradiation doses: Jsc: 1.0, 2. 1015, 3. 1016 (el/cm2), Voc: 4. 0, 5. 1015, 6. $1016(\mathrm{el} / \mathrm{cm} 2)$

In Figure 4, showing the photo current $\left(I_{f}(\lambda)\right)$, the curves 1 to 3 as a function of light intensity are compared, and it is shown that changes of photo current $\left(I_{f}(\lambda)\right)$ will occur for short-wave radiation region.

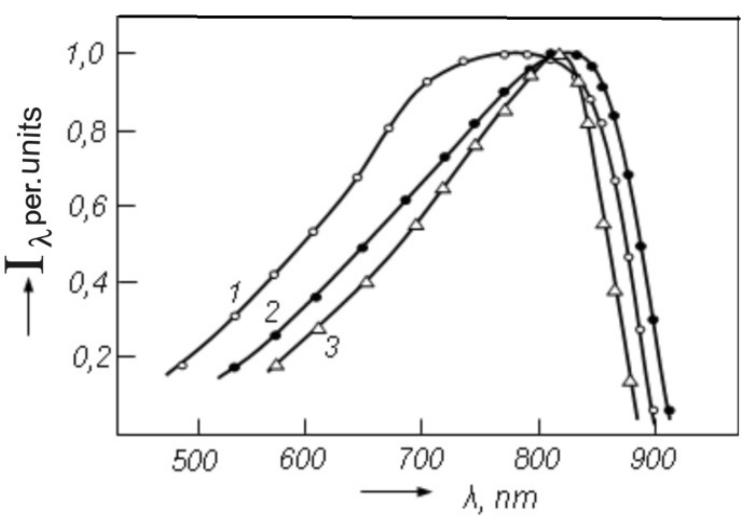

Fig. 4. Spectral characteristics at different irradiation doses: 1. $0,2.1015$ (el./cm2), 3. $1016(\mathrm{el} . / \mathrm{cm} 2)$

The obtained results confirm the theoretical and experimental results obtained in the hetero-junctions radiated by electrons with $1 \mathrm{MeV}$ energy [5]. Comparison of theoretical and practical research shows that the hetero-junction has the most part of solar radiation on p-GaAs-p-AlGaAs layer. Diffusion path $(L n)$ is decreased due to the radiation and loss of recombination in p-layer, (after radiation $L n$ decreases from 7.5 to $5 \mu \mathrm{m})$.

$\operatorname{Ln}=\sqrt{\frac{k T \mu \tau}{q}}-\frac{D=\frac{k T \mu}{q}}{\longrightarrow} \operatorname{Ln}=\sqrt{D \tau}$

where $L n$ and $D$ are the diffusion path and coefficient respectively.

\section{RESULTS AND DISCUSSION}

To provide maximum efficiency of solar cells, a $1016 \mathrm{~cm}$ thickness should be chosen for pAl0.75Ga0.25As layer. The comparison of these facts and the obtained results proves once more that the electron radiation ray generates defects on the $p$ $\mathrm{A} 10.75 \mathrm{Ga} 0.25 \mathrm{As}$ layer.

To determine the effect of the electron radiation ray on structural parameters, and the characteristics of solar cells, the V-I characteristic curve of solar cells in the presence of surface temperature have been studied before and after the radiation of electron radius in the temperature of $300^{\circ} \mathrm{C}$. As shown in Figure $5, I(V)$ depends on the radiation ray for small doses $\left(2 \times 1014 \mathrm{elec} / \mathrm{cm}^{2}\right)$ and will be as usual for $V \geq V d$ ( $V d$ is threshold voltage, curves 1 and 2). This means that, at first, the amount of electron ray irradiation may considered to be an error [6-7]. High dose radiations $\left(10^{16}-10^{17}\left(\mathrm{el} . / \mathrm{cm}^{2}\right)\right)$ causes changes to the V-I characteristic, especially appearing for voltage $V<V d$. To clarify the facts, $\log (I(V))$ is to be determined based on its dependence to the maximum radiation flow. It is shown that, for small voltages in the biased voltage direction, change will follow an exponential rate whereas for voltages over $0.6(\mathrm{~V})$, change will follow a linear rate.

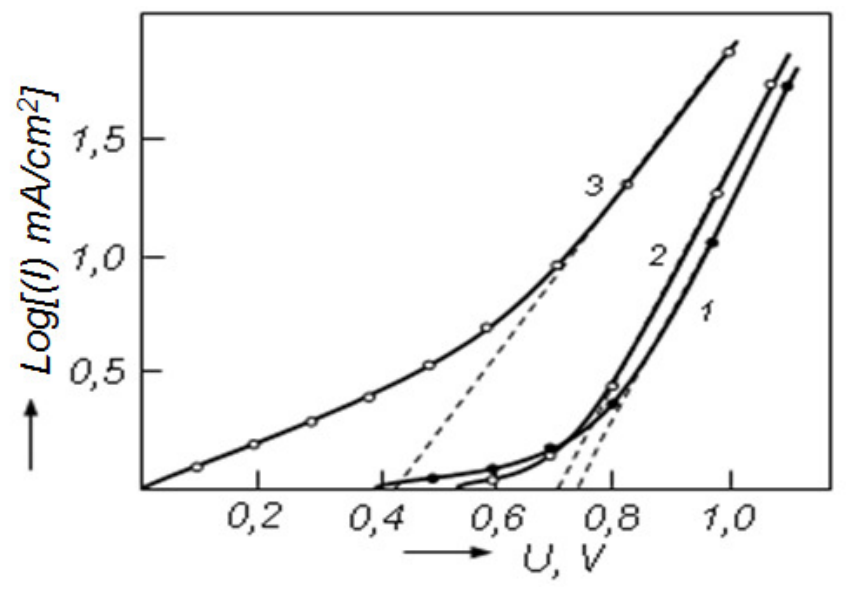

Fig. 5. V-I characteristics of solar cell before and after irradiation: 1. 1016 (el./cm2), 2. 1015 (el./cm2), 3.0

The time trend of $\beta$ and $J_{0}$ shows that the mechanism of current transfer depends on generation recombination and processes progressing in volumetric charging region. During the radiation of electron ray, (1012-1016 (elec/cm2)), $\beta$ and $J_{0}$, have the amount of $1.5-2.6$ and $10-8-10-7 \quad(A / \mathrm{cm} 2)$, respectively.

During the radiation of electron ray on hetero-junction, recombination centers will be produced in the divider layer [7]. In order to determine the photoactive concentration centers, the linear part of 1/C2 f(V0) dependence has been used and it has been revealed that before and after radiation, the concentration of the centers is equal to $4.5 \times 1015 \mathrm{~cm}-3$ and $1.1 \times 1015$ $\left(\Phi=1016\left(\mathrm{el} / \mathrm{cm}^{2}\right)\right)$, respectively. 
The thickness of potential barrier in the concentration level of impurity $(V D, N A, N D)$ is calculated and foung $0.9 \mathrm{~V}$, $1.5 \times 109 \mathrm{~cm}^{-3}$ and $2 \times 1017 \mathrm{~cm}^{-3}$. The relation $N_{A}-N_{D}<N_{f}$ shows that recombination concentration centers are generated on $\mathrm{p}$ GaAs layer and an increase of concentration of recombination centers at hetero-boundary and in sacrificial region is observed.

\section{SUMMARY AND CONCLUDING REMARKS}

Because of reduction of inner activity, production process, recombination and velocity of recombination will increase in the junction. To solve this problem the influence of accelerated electron ray on photo electric properties of AlGa-GaAs was investigated. A case study surface of about $2 \mathrm{~cm}^{2}$ was employed. Electron ray of ELIT-6 equipment was used. It was found that $J_{s c}$ and $\eta$ are decreasing due to the increase of electron ray dose whereas $V_{O C}$ is only slightly decreased. Changes of photo current $[I(\lambda)]$ was investigated in the shortwave radiation region. Diffusion path $(L n)$ is decreased due to radiation and loss of recombination in $\mathrm{p}$-layer. This process was performed in the temperature of $300^{\circ} C$. During the radiation of electron ray on hetero-junction, recombination centers were produced in the divider layer. Increase of concentration of recombination centers at hetero-boundary and in sacrificial region under the influence of radiation is observed.

\section{REFERENCES}

[1] A. Luque and S. Hegedus, Handbook of photovoltaic science and engineering, John Wiley and Sons, 2003.

[2] G. W. Crabtree, N. S. Lewis, "Solar energy conversion", Physics Today, 2007, Vol. 60, pp. 37-42, 2007.

[3] R. M. Nault, Basic research needs for solar energy utilization, Argonne National Laboratory, 2005.

[4] B. Burnett, The basic physics and design of III-V multijunction solar cells, U.S. Department of Energy National Center for Photovoltaics, 2002

[5] F. Dimroth et al., "Next generation GaInP/GaInAs/Ge multi-junction space solar cells", Proc. 17th Photo-voltaic European Conference, WIPMunich and ETZ-Florence, 2001
[6] V. M. Andreev, V. R. Larionov, V. D. Rumyantsev, O. M. Fedorova, Sh. Sh. Shamukhamedov, "pAlGaAs-pGaAs-nGaAs solar cells with efficiencies of 19 percent at AM 0 and 24 percent at AM 1.5", Pis'ma v Zhurnal Tekhnicheskoi Fiziki, Vol. 9, pp. 1251-1254, 1983

[7] R. Sahai, D. D. Edivall, J. S. Harris, "High efficiency AlGaAs/GaAs concentrator solar cells", Appl. Phys. Lett, Vol. 34, pp .147-149, 1979

[8] V. M. Andreev, B. V Egorov, V. M. Lantratov, V. D. Rumyantsev, Sh. Sh. Shamukhamedov, "Solar heterophotocells with increased p-n junction depth", Zhurnal Tekhnicheskoi Fiziki, Vol. 53, pp. 1658-1660, 1983

[9] G. H. Walker, E. J. Conway, "Short Circuit Current Change in Electron Irradiated GaAlAs/GaAs Solar Cells", Proc/Intern, Solar Energy Soc. Cong.-N.Y, Pergamon Press, pp. 575-579, 1978.

[10] B. V. Egorov, V. M. Lantratov, S. I. Troshkov, "Analysis of dark characteristics of solar cells on the basis of heterojunction AlGaAs/GaAs", In Coll.of Abst. 111 of USSR Conf. on Physical Processes in Semiconductor Heterojunctions. Odessa, Vol. 1, pp.200202,1982

\section{AUTHORS PROFILE}

Mosaddegh Sojoudi was born in 1958 in Azerbaijan, Iran. He received the B.Sc. and M.Sc. degrees from Tabriz University. Now, he is pursuing a Ph.D from the Institute of Radiation Problems of Azerbaijan National Academy of Science, Baku, Azerbaijan. He is a faculty member at the Electrical Engineering Department of Azerbaijan Higher Education and Research, Tabriz, Iran (ministry of power). His research is in the field of solar cell energy and distributed generation.

Rahim Madatov was born in 1949 in Shaki, Azerbaijan. He received the B.Sc. in physics from Azerbaijan nation Academy of science and the M.Sc and $\mathrm{Ph} . \mathrm{D}$ degrees in solar cell from Moscow state university, Russia, 1992. Dr. Madatov is an academic member of Radiation Problems of Azerbaijan National Academy of Science, Baku, Azerbaijan.

Tina Sojoudi was born in 1988. She is pursuing the B.Sc. degree in electrical engineering at I.A.U, Tabriz, Iran. Her areas of interest are in renewable energies, distribution systems optimization and planning, and distributed generation.

Payam Farhadi was born in 1985. He received the B.Sc. and M.Sc. degrees both in electrical engineering from I.A.U, in 2009-Ardebil and in 2011-Ahar, respectively. His research interests are distribution system planning and optimization, distributed generation and FACTS devices. Mr. Farhadi is an elite member of Young Researchers Club (YRC) in Iran, and a faculty member of I.A.U. at the Department of Electrical Engineering -Parsabad Moghan Branch, Parsabad Moghan, Iran. 